\title{
Do começo ao fim, caminhos que segui: itinerações no cuidado paliativo oncológico
}

\author{
Paths I have followed, from the beginning to the end: itinerations on \\ oncologic palliative care
}

Dayse Maria de Vasconcelos Rodrigues', Ana Lúcia Abrahão ${ }^{\mathbf{2}}$, Fernando Lopes Tavares de Lima1

DOI: $10.1590 / 0103-1104202012505$

RESUMO O objetivo desse estudo foi compreender a itineração de usuários com câncer em cuidados paliativos exclusivos pela rede de atenção à saúde, contemplando desde a suspeita diagnóstica até os cuidados paliativos exclusivos. Trata-se de pesquisa qualitativa, a partir de narrativas de vida de pacientes e familiares. Utilizaram-se seis entrevistas semiestruturadas e análise de conteúdo. Emergiram três categorias de análise: Caminhos pelo cuidado oncológico; Cuidados paliativos em oncologia: de mitos e tabus à realidade; e Autonomia e apoio social. Evidenciou-se uma multiplicidade de itinerações na busca por cuidado, não seguindo diretamente os trajetos previamente definidos pelos gestores do sistema de saúde. Além disso, verificou-se a necessidade de estabelecer uma comunicação clara e efetiva com esses sujeitos, esforçando-se na desmistificação do câncer e dos cuidados paliativos. Deve-se aprender a olhar para esses cidadãos de forma a ultrapassar seu corpo adoecido, enxergando-os como pessoas reais, com seus desejos, sentidos, protagonismos, e capacidade de ressignificar a sua própria existência e a sua forma de se perceber e se posicionar perante o mundo.

PALAVRAS-CHAVE Tempo para o tratamento. Acesso aos serviços de saúde. Neoplasia. Cuidado paliativo.

1 Instituto Nacional de Câncer José Alencar Gomes da Silva (Inca) - Rio de Janeiro (RJ), Brasil. flima@inca.gov.br

2 Universidade Federal Fluminenses (UFF) -

Niterói (RJ), Brasil.

\begin{abstract}
The objective of this study was to understand the itinerations of users with cancer in exclusive palliative care by the health care network, contemplating the diagnostic suspicion until exclusive palliative care. It is qualitative research, based on the life narrative of patients and family members. Semi-structured interviews and content analysis were used. Three categories of analysis have emerged: Pathways to cancer care; Palliative care in oncology: from myths and taboos to reality; and Autonomy and social support. A multiplicity of itinerations in the search for care was evidenced. It was verified that the course did not follow the paths previously defined by the managers of the health system. Besides, there was a need to establish clear and effective communication with these subjects, striving to demystify cancer and palliative care. One must learn to look at those subjects in a way to surpass their sick body, seeing them as real people, with their desires, senses, protagonisms, and capacity to re-signify their existence and their way of perceiving and positioning themselves before the world.
\end{abstract}

KEYWORDS Time-to-treatment. Health services accessibility. Neoplasm. Palliative care. 


\section{Introdução}

A Política Nacional para Prevenção e Controle do Câncer (PNPCC) reconhece o câncer como um problema de saúde pública no País $\mathbf{1}$, sendo estimada a incidência de 600 mil casos para $2019^{2}$. O cuidado oncológico demanda produção de um cuidado integral que inclui prevenção, detecção precoce, diagnóstico, tratamento e cuidados paliativos de forma oportuna, permitindo a continuidade do cuidado'

Para qualificá-lo, é essencial conhecer as histórias de vida das pessoas acometidas pela doença e identificar a construção dos caminhos em busca do cuidado, o que se tem denominado itinerário terapêutico. Entendido como os movimentos desencadeados pelos indivíduos a partir de uma sucessão de acontecimentos e tomadas de decisões que visam à preservação ou à recuperação da saúde 3 , o itinerário inicia na busca pela primeira consulta.

Historicamente, a expressão 'itinerário terapêutico' começou com Mechanice e Volkart ${ }^{\mathbf{4}}$. Eles compreendiam que o indivíduo orienta sua conduta para satisfazer suas necessidades de forma voluntária, racional e individualista, considerando o custo-benefício. Entretanto, a temática tem sido abordada de forma mais ampla, envolvendo questões que estão além da escolha individual, como, por exemplo, o nível socioeconômico ${ }^{5}$.

Estudar os itinerários serve como ferramenta de entendimento dos dispositivos de cuidados utilizados pelo usuário diante da enfermidade. Investigações apontam como os desfechos podem alterar a partir das escolhas do percurso por cuidado, sejam por profissionais, usuários e gestores ${ }^{6}$. Identificar como as pessoas adoecidas buscam auxílio para sanar suas necessidades é essencial para planejamento, organização e avaliação de serviços de saúde ${ }^{7,8}$. Uma das formas de conhecer esse itinerário é recorrer à sua narrativa, por retratar a experiência da busca por cuidados de saúde?.

Bonet $^{10}$, baseando-se em Tim Ingold, apresenta a alternativa de compreender esse percurso como um processo denominado 'itineração'. Nele, o deslocamento dos usuários estrutura um caminho próprio, que geralmente não coincide com o planejamento dos gestores. Ao se movimentarem pelos serviços, os indivíduos tomam decisões e, com elas, vão construindo uma história. Assim, o objetivo no esquema Ingoldiano adaptado por Bonet ${ }^{10}$ é entender o movimento entre os diferentes pontos da malha social, isto é, a itineração. Essa abordagem difere das demais por considerar a itineração como um processo dinâmico e construído pelos agentes envolvidos e suas interações, o que nos faz considerar o próprio sistema de saúde como um processo em construção por diferentes agentes não limitados aos profissionais do setor saúde ou gestores.

Diante do exposto, o objetivo deste estudo foi compreender a itineração de usuários com câncer em cuidados paliativos exclusivos a partir de suas narrativas de vida.

\section{Metodologia}

Trata-se de pesquisa exploratória com abordagem qualitativa, que proporciona uma melhor visão e compreensão do problema enfrentado ${ }^{11}$. Selecionou-se a análise de narrativas como método, visando esclarecer como determinadas ações são projetadas e executadas pelo indivíduo e compreender os motivos que o levou a estas ações ${ }^{12}$. Para Clandinin e Connely ${ }^{13}$, é 'uma forma de entender a experiência', resultando em uma coleta de histórias sobre o tema escolhido. As narrativas servem, nesse sentido, como base de reconhecimento dos movimentos desencadeados por indivíduos na preservação ou recuperação da saúde ${ }^{3}$.

$\mathrm{O}$ estudo foi realizado entre setembro e dezembro de 2018 no Hospital do Câncer IV (HCIV) do Instituto Nacional de Câncer José Alencar Gomes da Silva (Inca) no município do Rio de Janeiro. Diferentemente das demais unidades hospitalares do Inca, essa unidade se dedica integralmente aos 
cuidados paliativos oncológico exclusivos. A partir de uma amostragem por conveniência e saturação teórica ${ }^{\mathbf{1 4}}$, foram considerados elegíveis os pacientes e familiares em atendimento no HCIV, cientes da condição de cuidados paliativos exclusivos, de ambos os sexos, com idade igual ou superior a 18 anos, e que concordassem em participar da pesquisa. Dessa forma, quatro usuários em cuidados paliativos exclusivos (dois em assistência ambulatorial e dois em internação) e cinco familiares que participavam dos cuidados fizeram parte da investigação.

A produção e a coleta de dados foram feitas por entrevistas semiestruturadas, a partir de um roteiro com as seguintes questões norteadoras: 'Como foi o processo para o diagnóstico do câncer?'; 'Após a confirmação do diagnóstico, como foi o processo para iniciar o tratamento?'; 'Como foi o processo de tratamento do câncer?'; 'Como foi o processo de encaminhamento para os cuidados paliativos'; 'Pensando em todo esse percurso, como você compreende o cuidado que lhe foi prestado até esse momento?'. O pesquisador não ficou restrito ao roteiro e buscou aprofundar temas que surgiram das narrativas dos participantes, conforme indicação $0^{15,16}$. As entrevistas foram gravadas e transcritas para análise de conteúdo temática descrita por Bardin17, a partir do conceito de itinerações e malhas de Bonet ${ }^{10}$.

Na descrição dos resultados e discussão, optou-se por realizar, incialmente, um breve extrato das quatro narrativas, visando possibilitar a compreensão a respeito de cada história individualmente. Posteriormente, foi realizada a análise de conteúdo temática das entrevistas em três categorias empíricas: Caminhos pelo cuidado oncológico; Cuidados paliativos em oncologia: de mitos e tabus à realidade; $\mathrm{e}$ Autonomia e apoio social.

O estudo foi aprovado pelo Comitê de Ética em Pesquisa do Inca sob o número CAAE: 93134318.8.0000.5274; os nomes apresentados são fictícios para preservar a identidade dos participantes.

\section{Resultados e discussão}

\section{Extrato das narrativas}

As narrativas indicam que as itinerações criadas, apesar de apresentarem pontos em comum relacionadas com a própria organização do sistema de saúde, possuem particularidades, evidenciando a necessidade de compreender o adoecer, buscando pela cura como algo singular e subjetivo do ser humano, conforme apontou Bonet ${ }^{10}$.

\section{GILBERTO}

Agente de limpeza urbana, 54 anos, casado e soropositivo para Vírus da Imunodeficiência Humana (HIV). Diagnosticado com câncer de peritônio, está no Inca há um mês em cuidados paliativos exclusivos. É conhecido pela equipe pelas guirlandas que confecciona no espaço Curiosação, local destinado a atividades de artes para que pacientes e cuidadores saiam do confinamento do quarto. Encontrava-se internado, mas ativo e participativo das atividades.

Começou sua itineração na rede privada em fevereiro de 2017, após crescimento 'anormal' da barriga. Procurou cuidados médicos e foi diagnosticado com ascite difusa. Depois de realizada biopsia, foi confirmado o diagnóstico de câncer. Fez o tratamento por um ano sem resultados satisfatórios. Foi, então, encaminhado à rede pública, sendo regulado pela Clínica da Família (CF) do seu território. Em outubro de 2018, deu entrada no Inca, sendo prontamente indicado para o cuidado paliativo exclusivo no HCIV devido ao estadiamento da doença.

\section{CAETANO}

Solteiro, 51 anos, morador de Duque de Caxias. Possui ensino fundamental incompleto, trabalhava de 'bicos', portador de paraplegia há 30 anos por perfuração por arma de fogo. Por demonstrar dificuldade em expressar total entendimento sobre sua condição clínica, a 
entrevista foi realizada, sob seu consentimento, com a sua irmã, cuidadora principal.

Sua itineração teve início na Unidade de Pronto Atendimento (UPA), a partir do surgimento de 'cisto nas nádegas'. Foi medicado e encaminhado para a CF, que tratou a lesão com trocas de curativos. Sem apresentar melhora, buscou assistência médica na emergência de um hospital geral do Rio de Janeiro, ficando por cinco dias. Foi transferido para o hospital geral próximo à sua residência, onde permaneceu sete meses tratando a lesão como se fosse uma escara, sem diagnóstico de câncer.

Devido à ineficácia do tratamento, foi encaminhado para uma clínica de dermatologia de um terceiro hospital geral, que sugeriu à família uma avaliação oncológica. Em novembro de 2018, foi diagnosticado com câncer de pele do períneo em região sacra, sendo encaminhado ao Inca. Na primeira consulta, foi encaminhado ao HCIV para iniciar os cuidados paliativos exclusivos devido ao estadiamento da doença. Encontrava-se internado nesta unidade.

\section{MILTON}

Homem, 58 anos, separado, uma filha, morador do bairro de Bangu, ensino fundamental incompleto e ajudante de caminhão. Devido à dificuldade de comunicação, foi dada, com seu consentimento, voz à filha e à irmã.

O início da itineração se deu por queixa de dor de dente, tratada em três consultas médicas como simples inflamação. Diante da não resolução, a família o inscreveu na CF de seu território, que o encaminhou para o Centro de Especialidades Odontológicas, onde realizou a biópsia e diagnosticou um câncer bucal. Em agosto de 2018, foi encaminhado e, após um mês, matriculado no Inca. Devido ao estado avançado da doença, foi encaminhado para cuidados paliativos exclusivos no HCIV, onde se encontra em cuidados ambulatoriais.

\section{ELIS}

Solteira, 50 anos, uma filha adotiva, moradora do bairro de Piedade. Possui ensino fundamental completo e trabalhava como babá e cuidadora de idosos. Demonstrou interesse em manter um rico diálogo, não se constrangendo em falar de si. Uma sobrinha, que a tem acompanhando, também participou da entrevista. Evidenciou-se que a família participa do cuidado de forma ativa, o que, em certos momentos, gera incômodo na usuária, que afirma ter perdido sua liberdade.

Relatou usar os serviços públicos continuamente por meio da CF, realizando seus exames preventivos. Em 2015, com queixa de sangramento intenso e aumento da barriga, fez alguns exames, sendo identificada a necessidade de retirada de um mioma, realizada em um hospital geral do Rio de Janeiro. Durante a cirurgia, levantou-se a hipótese de haver um câncer associado ao mioma, sendo então realizada biópsia.

Em maio de 2015, após confirmação diagnóstica de câncer de endométrio, foi encaminhada ao Inca, realizando cirurgia para remoção do tumor, seguida de tratamento radioterápico e quimioterápico. Apesar do tratamento, teve progressão da doença e um quadro de trombose, sendo encaminhada para os cuidados paliativos exclusivos em julho de 2018, nos quais se encontra em assistência ambulatorial.

\section{Análise do conteúdo}

\section{CAMINHOS PELO CUIDADO ONCOLÓGICO}

Descrever a busca por cuidado é tarefa complexa, devido às concepções sobre a doença e os diferentes contextos que levam as pessoas a construírem seus percursos ${ }^{\mathbf{1 8}}$. Porém, tais caminhos não são simplesmente resultado de escolhas pessoais. Outras questões interferem nesse processo, como a disponibilidade da assistência médica, capacidade financeira, resultado do tratamento popular e os modos como as pessoas percebem o problema ${ }^{19}$.

Bonet ${ }^{10}$ sugere que toda busca por saúde é construída a partir de processos abertos, em 
permanente fluxo e propenso a improvisações criativas pelos sujeitos envolvidos. Conforme afirma Ingold ${ }^{20}$, esse improvisar é seguir os modos do mundo à medida que eles se desenrolam, e não conectar em retrospecto, em uma série de pontos já percorridos.

$\mathrm{O}$ adoecimento mobiliza diferentes alternativas de escolha terapêutica, sejam informais, populares ou profissionais, escolhidas em função das disponibilidades e explicações culturalmente aceitas ${ }^{21}$. Portanto, esse caminhar não se forma apenas por caminhos predeterminados, mas por uma rede viva, mutante e flexível, indo, muitas vezes, no sentido oposto das estruturas rígidas oferecidas pelos serviços de saúde. A rede, portanto, não é fechada, impermeável, e, sim, um agrupamento de linhas fortemente unificadas, com alguns pontos em aberto, que se agrupam com outras linhas de outros agrupamentos 22. Assim, apesar das redes construídas previamente ao adoecimento terem interferido nas itinerações, novas conexões reestruturaram essas redes.

Cheguei aqui, Deus ajudou. Eu conhecia uma pessoa, minha irmã também... enfermeira de lá mesmo, que ajudou a gente. Aí, outras pessoas também, que é 'grandão'... aí foi, consegui ficar aqui. (Caso Caetano).

De forma geral, os caminhos trilhados refletiram as formas de regulação do acesso definidas pelo gestor, seguindo a lógica de serviços apoiada na hierarquização da doença. Entretanto, analisando-se as particularidades dos casos, observou-se que as itinerações foram mais complexas do que as previstas pela regulação formal, que deve ser compreendida apenas como uma das lógicas regulatórias, havendo ainda a regulação profissional, a clientelístico-eleitoreira e a leiga ${ }^{23}$. Neste estudo, essas formas se apresentaram simultaneamente, caracterizando a complexidade das itinerações em busca do cuidado oncológico em uma rede viva ainda em organização. A construção de redes vivas ressalta que os usuários, enquanto redes de existências, produzem-se a partir dos contatos que são gerados com o mundo, constituindo certas formas éticas existenciais e modos de conduzir, por si, a produção de cuidado, disputando em tempo integral com as diferentes lógicas de existir impostas pelas instituições ${ }^{\mathbf{2 4}}$.

As itinerações foram demarcadas por barreiras de acesso ao tratamento, que se apresentaram desde antes de estabelecido o diagnóstico e permaneceram até a data da entrevista. Essas barreiras contribuem para o acirramento da "tensão entre o usuário-fabricado e usuário-fabricador"23. Pela primeira lógica, os usuários são vistos como alvo de estratégias de disciplinamento, e seu fluxo pelo sistema de saúde é normatizado pelos gestores. O que corre por fora desse fluxo seria uma disfunção a ser corrigida. Porém, precisamos reconhecer que as pessoas 'transgridem a regra' o tempo todo, emergindo a figura viva do usurário-fabricador ${ }^{23}$.

Eu estava sentindo, assim, estranho. Meu irmão só com antibiótico e cheirando mal. Aí, eu falei meu irmão não vai pra casa não e nem pra abrigo - meu irmão não é morador de rua - só vou tirar ele daqui quando eu souber o que é que ele tem. (Caso Caetano).

Percebe-se a necessidade de movimentos de construção e reconstrução do caminhar, tornando os sujeitos andarilhos por saúde, que percorrerem caminhos sem destino certo e nada lineares. Skaba ${ }^{25}$, em 2003, identificou que usuárias com câncer de mama tiveram trajetos penosos para iniciarem o tratamento. Uma das usuárias peregrinou por dois anos em seis serviços de saúde, sem definição para seu tratamento. Infelizmente, essa situação ainda é comum.

Sabe-se que, formalmente, a atenção básica é o primeiro contato dos usuários com a rede e coordena o caminhar pelos outros pontos de atenção. Os primeiros sinais e sintomas devem ser identificados nesse nível de atenção, que solicita exames para comprovação diagnóstica' ${ }^{1}$. Porém, a ideia de porta de entrada única 
é inconsistente com o modelo que pretende realizar a integralidade das ações individuais e coletivas em sua plenitude 26,27 .

Eu estava no particular, porque eu passava mal em casa e corria para o particular, porque a CF não atende coisa assim, é só consulta ou remédio [...] só que chegando no particular, eles me falaram que não podiam fazer nada, pois o câncer já estava muito espalhado...eles falaram que eu tinha que vir para o hospital do câncer mesmo. [...] fui para CFe eles falaram que não gostavam de atender, porque tinha um particular interferindo. (Caso Gilberto).

A escolha em utilizar, inicialmente, o setor privado parte da crença de que o cuidado se dá mais rapidamente. Porém, segundo a percepção do usuário, isso resultou em um fator dificultador na continuidade do cuidado, haja vista os limites da integração entre os setores privado e público. Mesmo já estando em tratamento oncológico, o participante precisou ter o diagnóstico confirmado na CF para poder ser encaminhado ao centro de referência, o que pode ter aumentado o tempo pata tratamento.

Além das condições objetivas de sobrevivência, a compreensão do processo de adoecimento e cura é influenciada pelos paradigmas que regem a saúde e a doença ${ }^{28}$. Segundo Foucault ${ }^{29}$, o corpo é um texto com possibilidades para inúmeras leituras. Esse corpo adoecido é capaz de emitir significados tanto para o doente, quanto para o médico. Este, a partir da racionalização biomédica, observa o corpo como uma máquina que, ao apresentar avaria, deve ser consertada. Esse olhar fragmentado faz com que ele perca de vista o doente e a interrelação sociocultural, psicossocial e espiritual que permeia qualquer doença $\mathrm{a}^{30}$.

A gente pensava que era dor de dente. la no médico, comprava remédio e tomava para desinflamar o dente. Melhorava e depois voltava. [...] Só tratava como dente inflamado [...] começou como se fosse uma espinha que foi se alastrando, só que muito rápido e foi ficando assim, foi abrindo e estourou e agora está até na língua dele. (Caso Milton).
Independentemente de como é feita e em que momento é realizada a busca por cuidado, tem-se sempre que se atentar a olhar o indivíduo além do corpo adoecido. Vê-lo e reconhecê-lo como corpo vivo situado no mundo de suas experiências vividas que devem ser valorizadas. Nos cuidados paliativos, esse cuidar visa compreender todas as necessidades do indivíduo, dentro dos seus limites possíveis, considerando-o sempre como um ser integral ${ }^{31}$.

A partir da análise de narrativas, compreende-se que a complexidade das itinerações ultrapassam a norma estabelecida. No cotidiano, o cidadão encontra barreiras que dificultam o acesso: disponibilidade de serviços e sua distribuição geográfica; disponibilidade e qualidade da força de trabalho; barreiras tecnológicas; mecanismos de financiamento; e o próprio modelo assistencial ${ }^{32}$.

\section{CUIDADO PALIATIVO EM ONCOLOGIA: DE MITOS E TABUS À REALIDADE}

O câncer é carregado de mitos e tabus, em um contexto histórico construído sobre o medo e o futuro incerto e frágil. Os principais sintomas são tidos como tipicamente invisíveis até o último estágio, quando o prognóstico não é favorável. Não raro, é descoberto por acaso, em estágio avançado, sem ter qualquer sintoma anterior ${ }^{32}$.

Eles falaram primeiro para elas [apontando para sobrinha e fazendo referência também as irmãs]. Elas se desesperam mais do que eu. Eu não fiquei desesperada, porque tenho certeza que papai do céu vai mandar a vitória, eu creio. (Caso Elis).

A dificuldade do diagnóstico precoce, a despeito de todo o progresso dos tratamentos, reforça o mito do câncer como doença incurável, equivalendo a uma sentença de morte no imaginário popular ${ }^{33}$. Ter a confirmação diagnóstica faz com que o indivíduo inicie um conflito interno na tentativa de entender as 
razões para seu adoecimento: seria 'doença-maldição' ou 'doença-punição'?

Na doença-maldição, a doença é vista como um acidente, uma fatalidade, uma injustiça. No caso da doença-punição, o adoecimento é visto como uma consequência necessária que o próprio individuo ou grupo provocou ${ }^{34}$.

Ele nunca ficou doente e por isso não ia ao médico. A primeira vez foi essa. Só foi para ver isso porque o tumor estava ficando cada vez maior e ele não podia mais esconder [...] só estava eu, e aí ela [médica] falou para mim que estava muito avançado, falou que ele não tinha mais cura [...] ele não iria se curar, porque não iria ter jeito, ia morrer disso. (Caso Milton).

Se o câncer é carregado de mitos e tabus sobre a finitude, nos cuidados paliativos isso se amplia. Por isso, é necessário desmitificar o que é falado ou esperado dessa modalidade de cuidado. Tanto para a Organização Mundial da Saúde quanto para o Ministério da Saúde, os cuidados paliativos são uma abordagem multidisciplinar que objetiva a melhoria da qualidade de vida dos pacientes e familiares perante uma doença fatal, mediante prevenção e alívio do sofrimento por meio da identificação precoce, avaliação impecável e tratamento de dor e demais sintomas físicos, sociais, psicológicos e espirituais ${ }^{35,36}$. Devem ser centrados no indivíduo, e não em sua doença; iniciados desde o diagnóstico, passando pelo tratamento curativo, até o momento em que a possibilidade de cura é nula ${ }^{36}$.

De fato, como uma nova forma de gestão da morte, os cuidados paliativos têm-se constituído como uma nova medicina, apresentando uma dimensão crítica à fragmentação de seu olhar no processo de cuidado dos pacientes e familiares ${ }^{37}$. Porém, apesar dos princípios dos cuidados paliativos estarem bem estabelecidos, o medo da morte é reforçado nessa modalidade de cuidado. Identificou-se que muito do medo associado aos cuidados paliativos deu-se pela forma de como é feita a transição do tratamento curativo para paliativo.
[...] ele veio para cá [HCIV] porque lá no outro Inca só fica quem opera e trata. Encaminharam para cá, porque a doença dele está avançada e não tem mais recurso. Aqui é para acompanhar nas dores, nos vômitos, se tiver falta de ar [...] e tem também o acompanhamento com a família. [...] Fui na enfermeira de lá, entrei sem ele e ela começou dizendo que aqui $[\mathrm{HCIV}]$ o procedimento era para dar apoio, suporte para família e que a questão da dor ia ser resolvida. E ela foi bem atenciosa. Eu entendi que aqui vão tentar dar um conforto a ele. (Caso Milton).

A narrativa reforça a importância em considerar a compreensão dos envolvidos na produção desse cuidado. Ajuda refletir como, na mesma instituição, podem existir modelos de cuidado diferentes, porém produzidos com a mesma intencionalidade, que é assistir o usuário em seu processo de adoecimento. Além disso, destaca-se, nessa narrativa, o reforço da dicotomia entre curativo-paliativo na fala de um profissional. A existência de um Inca que cura e outro que cuida faz com que o curar pareça estar afastado do cuidar, o que é, no mínimo, contraditório. Diante desse cenário, é importante encontrar maneiras para romper essa dicotomia e produzir um cuidado integral, ultrapassando o modelo tecnicista biomédico e fortalecendo o acolhimento, a criação dos vínculos e a escuta ativa do sujeito.

Além do que é dito, também há um efeito do que não é dito aos usuários e seus familiares sobre câncer e cuidados paliativos na perpetuação ou dissolução de mitos e tabus. Sontag ${ }^{33}$ destacou que alguns profissionais (e familiares) consideram melhor poupar as pessoas fadadas à morte da informação de que estão a morrer, acreditando que a verdade seria insuportável. Segundo a autora, na França e na Itália, é regra entre médicos comunicar o diagnóstico de câncer à família do paciente, mas não a ele. Parece que no Brasil, mesmo que informalmente, também o é.

Aí, ele [paciente] falou para mim...O que é que é o Inca? Se eu tiver com alguma coisa me fale [...] 
não tive coragem de falar para ele. [...] ele não sabe nada - Meu Deus, meu irmão está sofrendo muito. Os médicos viram que ele é muito sensível e por isso me pediram para eu não falar nada para ele. (Caso Caetano).

Essa conspiração de silêncio construída por profissionais e familiares ao redor do usuário com câncer em processo de finitude vem na tentativa de evitar a ideia da morte, afastando-a tanto quanto possível, reprimindo a ideia indesejada ou assumindo uma crença inabalável em nossa própria imortalidade ${ }^{38}$. Isso faz com que essa enfermidade continue sendo tratada como um predador invisível e maligno, e não só como uma doença. A solução não pode estar em deixar de contar a verdade, mas em retificar o conceito da doença, desmistificá-la ${ }^{33}$.

A médica falou para mim que o câncer estava muito avançado, que ela ia encaminhar para o HCIV e que lá a enfermeira iria me explicar [o porquê do encaminhamento]. (Caso Milton).

A estratégia de falar pouco, ou quase nada, sobre a situação de adoecimento, terceirizando a comunicação pela má notícia para outras pessoas, apenas evidencia um certo despreparo, desconhecimento, desinteresse ou até falta de empatia, o que, de uma forma ou de outra, pode produzir indiretamente um descuidado a esse indivíduo ${ }^{39}$.

A morte é provocadora de incômodos, e a maneira de olhá-la depende do momento, da cultura e dos sentidos dados a ela ${ }^{40}$. Na cultura ocidental contemporânea, mesmo sabendo que não poderemos evitá-la, ainda consideramos um tabu conversar sobre ela $\mathbf{4 0}^{\mathbf{0}}$. No processo de cuidado, principalmente de pacientes em cuidados paliativos exclusivos, é necessário manter o diálogo aberto, falar sobre tudo que é de direito do sujeito e tudo que ele desejar saber.

\section{AUTONOMIA E APOIO SOCIAL}

O câncer e seu tratamento afetam a qualidade de vida de pacientes e familiares. Além da dor e de outros desconfortos físicos, tem impacto da ordem psicossocial, que são ampliados pela precariedade do sistema de proteção social no Brasil. Acarreta, assim, uma importante mudança de vida, com a perda da autonomia destacada pelos participantes.

Meu pai sempre trabalhou, ele nunca dependeu de ajuda de ninguém e agora está dependendo até para troca de roupa, tomar banho, comer. [...] fiquei perguntando se ele estava com dor, pedindo para ele balançar cabeça que sim ou que não e ele respondia que não. Mas ele queria mostrar para mim um lencinho para eu poder comprar e ele usar. Estava querendo explicar e eu não conseguia entender. Então teve uma hora que ele levantou com raiva e soltou a sonda, e a dieta derramou e sujou tudo lá e ele não quis comer mais e nem ficar lá na salinha. (Caso Milton).

Esse sujeito, ao se ver doente, percebe-se limitado, tanto economicamente quanto fisicamente. Essas limitações colocam em causa um dos pilares básicos para a sua atribuição de sentido existencial, que é sua autonomia, seu ser no mundo, sua liberdade de agir, decidir sobre sua vida e suas escolhas, isto é, sua itineração.

Destacou-se também, diante dessa vulnerabilidade na autonomia, a importância do apoio social ao sujeito com câncer em cuidados paliativos exclusivos para desenvolver conforto, segurança, carinho. Nesse sentido, a família torna-se parte do processo terapêutico ${ }^{41}$. Por outro lado, verificou-se que a família, apesar do apoio dado ao paciente, pode se posicionar de forma paternalista, passando a tomar decisões que o privam do exercício da autonomia, apropriando-se, de forma involuntária, do corpo e dos desejos do outro.

Uma coisa que me incomoda muito desde que fiquei assim é a família. Ela é maravilhosa, mas desde que fiquei doente eu perdi a minha liberdade de fazer as coisas do meu jeito e na hora que eu gosto [...] eles querem mandar nos meus horários de dormir, acordar, comer [...] isso me deixa triste demais. Para mim é pior do que ficar doente do jeito que 
estou [...] eu digo que não quero tal coisa, mas aí decidem por mim e isso me deixa triste [...] eu só queria que entendessem que minhas prioridades mudaram e não estou no momento de me aborrecer por coisas tão pequenas. Queria que entendam que eu que agradeço muito o cuidado que têm para mim, mas que preciso ser ouvida e isso me deixa depressiva. (Caso Elis).

O cuidado não pode estar focado exclusivamente na doença e na busca pela cura ${ }^{42}$. Quando focamos o olhar para as pessoas em cuidados paliativos exclusivos, devemos nos ater a olhá-las e reconhecê-las como sujeito, corpo vivo situado no mundo de suas experiências, valorizando-as, e não as ignorando. Reconhecer que cada ação desse sujeito possui sentido e intencionalidade, não podendo ser vista com desprezo. Deve-se preservá-lo como sujeito autônomo, mesmo limitado pela doença, porém capaz de decidir sobre sua itineração.

Além dos efeitos diretos na vida do usuário, o processo de adoecimento por câncer interfere diretamente no cotidiano da rede social de suporte. Sofrimentos de diversas dimensões acometem tanto os portadores da doença como seus familiares e cuidadores. Entender o impacto do câncer nos indivíduos é essencial para estabelecer estratégias para enfrentar os problemas e para adaptar-se a essas mudanças.

Tive que me mudar correndo, porque falaram que iam dar alta para ele. Tive que me mudar para uma casa perto dele, porque queriam mandar ele para casa e como ele mora só e só tenho eu de irmã. (Caso Caetano).

O indivíduo em cuidado paliativo oncológico transita por dois locais distintos: 1) o hospital, nos momentos em que precisa controlar alguns sintomas, como dor, vômito ou hemorragias; e 2) sua casa, o que é mais desejado, pois é no lar que normalmente sentem-se mais seguros, tranquilos, pelo aconchego do ambiente familiar e pela liberdade para o cuidado nesse processo de finitude. Nos dois ambientes, os familiares precisam fazer rearranjos para conseguir participar do cuidado. Isso não significa algo fácil e tranquilo devido à complexidade desse cuidado tão específico. No entanto, ao se ver diante dessa nova maneira de viver e participar do cotidiano de seu ente querido, esses familiares enfrentam momentos de sofrimento, tendo suas vidas modificadas e afetadas pela proximidade da morte ${ }^{43}$. Na complexidade da assistência paliativa, cada ator (profissionais, pacientes e familiares) deve incorporar um papel e desempenhá-lo adequadamente para a produção coletiva da boa morte'37.

Todavia, há aqueles que são e estão próximos do sujeito em processo de finitude e que, muitas vezes, não têm capacidade emocional de apoiá-lo e confortá-lo. Acham difícil apertar a mão ou acariciá-lo, proporcionar-lhe uma sensação de proteção e pertencimento. Muito disso é devido ao impacto que a visão de uma pessoa moribunda é capaz de produzir no outro, abalando as fantasias defensivas que as pessoas constroem como uma muralha contra a ideia de sua própria morte ${ }^{\mathbf{3 8}}$. Isso amplifica $\mathrm{o}$ sentimento de solidão desses pacientes.

Não tive filho, criei meus irmãos carregando peso na feira, fazia faxina, fazia tudo para ajudar, desde os oitos anos. Tenho sobrinhos, só que é aquela história [...] as vezes a gente ajuda muitas pessoas, aí bate um vazio, porque não tem aquilo de ficar aqui comigo, pelo menos para vir visitar às vezes. Calha até de ligar para mim, mas não vem para visitar. (Caso Gilberto).

As vivências e os sentimentos, tanto do doente como da família, traduzem-se em preocupação, medo da morte, tristeza, dor, sentimento de impotência, negação e raiva. Existe uma nova situação imposta, com a qual terão que lidar, a despeito de tudo. Esses familiares, estão literalmente em sofrimento pela eminência da morte, tal como o próprio doente, pois estão fragilizados e sofrem com a angústia da separação. Além disso, mesmo diante de sua situação, o indivíduo adoecido se vê, muitas vezes, responsável em organizar a 
vida daqueles que fazem parte do seu convivo familiar, para que a dor da sua partida seja um pouco menos dolorosa para os que ficam.

Eu me preocupo muito, já falei com a esposa se acontecer algo, o que ela tem de fazer e para isso já deixei procuração para ela se cuidar e cuidar de tudo. (Caso Gilberto).

Eu moro com minha filha do coração e vivo um dia de cada vez, na expectativa e na ansiedade da formatura da minha menina. [...] ela não quer nem ouvir quando eu comento que caso aconteça algo eu vou estar com ela naquele momento [...] ela fala que nem posso fazer isso com ela, então só me resta esperar meu milagre e estar lá na formatura da minha menina. (Caso Elis).

O apoio social tem tomado grande importância nos cuidados paliativos, sendo considerado como uma de suas tríades, juntamente com a comunicação eficaz e o controle dos sintomas; pois, estar doente e ver os nossos familiares preocupados, em sofrimento ou em dificuldade, não contribui para a serenidade $\mathbf{4 4}$. Isso gera um peso suplementar que não pode ser menosprezado. Se perceberem que a família está apoiada, esse sofrimento é atenuado.

\section{Considerações finais}

O presente estudo apresentou uma multiplicidade de itinerações de usuários em cuidados paliativos oncológicos exclusivos e seus familiares na busca por cuidado. Verificou-se que o caminhar pela rede de atenção não seguiu os trajetos previamente definidos pelos gestores do sistema de saúde, haja vista que nem sempre a rede posta é a rede que absorve, acolhe ou é resolutiva.
Identificaram-se dificuldades quanto ao diagnóstico pelos profissionais nos diferentes espaços da rede de atenção à saúde, o que pode ter levado à chegada tardia dos usuários na unidade de tratamento do câncer. Redes informais dos usuários e dos profissionais, sejam previamente ou recém-construídas, direcionaram os caminhos do cuidado.

Como limitação do estudo, podemos destacar a restrição do número de participantes e do cenário de pesquisa, o que apresenta dificuldades para generalização dos resultados para outras realidades.

Diante das narrativas apresentadas, portanto, verifica-se a necessidade de estabelecer uma comunicação clara e efetiva com esses sujeitos, esforçando-se na desmistificação do câncer e dos cuidados paliativos. Deve-se aprender a olhar para esses sujeitos de forma a ultrapassar seu corpo adoecido, enxergando-os como pessoas reais, com seus desejos, sentidos, protagonismos, e capacidade de ressignificar a sua própria existência e a sua forma de se perceber e se posicionar perante o mundo, nesse momento tão singular no qual continuam a construir sua itineração pela vida.

\section{Colaboradores}

Rodrigues DMV (0000-0003-3046-4589)* contribuiu para concepção e planejamento do estudo, coleta dos dados, análise e interpretação dos dados e elaboração do manuscrito. Abrahão AL (0000-0002-0820-4329) * e Lima FLT (0000-0002-8618-7608)* contribuíram para a coleta dos dados contribuiu para concepção e planejamento do estudo, análise e interpretação dos dados e revisão do manuscrito. 


\section{Referências}

1. Brasil. Ministério da Saúde. Portaria no 874, de 16 de maio de 2013. Institui a Política Nacional para a prevenção e Controle do Câncer na Rede de Atenção à Saúde das Pessoas com Doenças Crônicas no âmbito do Sistema Único de Saúde (SUS) [internet]. Diário Oficial da União. 17 Maio 2013. [acesso em 2020 abr 6]. Disponível em: http://bvsms.saude.gov.br/bvs/ saudelegis/gm/2013/prt0874_16_05_2013.html.

2. Instituto Nacional de Câncer José Alencar Gomes da Silva. Estimativa 2018: incidência de câncer no Brasil. Rio de Janeiro: INCA; 2017.

3. Cabral ALLV, Martinez-Hemáez A, Andrade EIG, et al. Itinerários terapêuticos: o estado da arte da produção científica no Brasil. Ciênc. Saúde Colet. 2011; 16(11):4433-4442.

4. Mechanic D, Volkart EH. Stress, illness behavior, and the sick role. Am. Sociol. Rev. 1961; 26(1):51-58.

5. Oliveira EXG, Melo ECP, Pinheiro RS, et al. Acesso à assistência oncológica: mapeamento dos fluxos origem-destino das internações e dos atendimentos ambulatoriais. O caso do câncer de mama. Cad. Saúde Pública. 2011; 27(2):317-326.

6. Hadad ACAC, Jorge AO, Melo EM. A construção de redes vivas no percurso de usuários e familiares, vítimas de trauma, em sua trajetória na busca pelo cuidado. Rev. méd. Minas Gerais. 2016; 26(supl8):S107-S111.

7. Silva LMV, Formigli VLA, Cerqueira MP, et al. O processo de distritalização e a utilização de serviços de saúde - avaliação do caso de Pau da Lima, Salvador, Bahia, Brasil. Cad. Saúde Pública. 1995; 11(1):72-84.

8. Travassos C, Viacava F, Pinheiro R, et al. Utilização dos serviços de saúde no Brasil: gênero, características familiares e condição social. Rev. panam. salud pública. 2002; 11(5/6):365-373.

9. Ferreira DC, Silva GA. Caminhos do cuidado: itinerários de pessoas que convivem com HIV. Ciênc. Saúde Colet. 2012; 17(11):3087-3098.
10. Bonet O. Itinerações e malhas para pensar os itinerários de cuidado. A propósito de Tim Ingold. Sociol. Antropol. 2014; 4(2):327-350.

11. Malhortra NK, Rocha I, Laudisio MC, et al. Introdução a pesquisa de marketing. São Paulo: Pearson; 2012.

12. Weller W, Zardo SP. Entrevista narrativa com especialistas: aportes metodológicos e exemplificação. Rev Faeeba: Educ Contemp. 2013; 22(40):131-143.

13. Clandinin DJ, Connelly FM. Narrative inquiry: experience and story in qualitative research. San Francisco: Jossey-Bass; 2000.

14. Fontanella BJB, Luchesi BM, Saidel MGB, et al. Amostragem em pesquisas qualitativas: proposta de procedimentos para constatar saturação teórica. Cad. Saúde Pública. 2011; 27(2):388-394.

15. Cruz Neto O. O trabalho de campo como descoberta e criação. In: Minayo MCS. Pesquisa Social: teoria, métodos e criatividade. 21. ed. Petrópolis: Vozes; 2002. p. 51-66.

16. Muylaert CJ, Sarubbi Jr V, Gallo PR, et al. Entrevistas narrativas: um importante recurso em pesquisa qualitativa. Rev. Esc. Enferm. USP. 2014; 48(esp2):184189.

17. Bardin L. Análise de Conteúdo. Lisboa: Edições 70; 2011.

18. Silva NEK, Figueiredo WS, Sancho LG. Entre fluxos e projetos terapêuticos: revisitando as noções de linha do cuidado em saúde e itinerários terapêuticos. Ciênc. Saúde Colet. 2016; 21(3):843-852.

19. Helman CG. Cultura, saúde e doença. 4. ed. Porto Alegre: Artes Médicas; 2003.

20. Ingold T. Ambientes para la vida: Coversaciones sobre humanidad, conocimiento y antropología. Montevideo: Trilce; 2012. 
21. Gerhardt TE. Itinerários terapêuticos em situações de pobreza: diversidade e pluralidade. Cad. Saúde Pública. 2006; 22(11):2449-2463.

22. Ingold T. Being alive: essays on movement, knowledge and description. Londres: Routledge; 2011.

23. Cecílio OCL. Escolhas para Inovarmos na Produção do Cuidado, das Práticas e do Conhecimento: como não fazermos "mais do mesmo"? Saúde Soc. 2012; 21(2):280-289.

24. Merhy EE, Gomes MPC, Silva E, et al. Redes Vivas: multiplicidades girando as existências, sinais da rua. Implicações para a produção do cuidado e a produção do conhecimento em saúde. Divulg. saúde debate. 2014; (52):146-152.

25. Skaba MMVF. Compreendendo a trajetória de mulheres em busca do diagnóstico e tratamento do câncer de mama: uma perspectiva socioantropológica [tese]. Rio de Janeiro: Instituto Fernandes Figueira, Fundação Oswaldo Cruz; 2003.

26. Mehry EE, Chakkour M, Stéfano E, et al. Em busca de ferramentas analisadoras das tecnologias em saúde: a informação e o dia a dia de um serviço, interrogando e gerindo trabalho em saúde. In: Merhy EE, Onocko R, organizadores. Agir em saúde: um desafio para o público. São Paulo: Hucitec; 1997. p. 113-150.

27. Cecílio OCL. As necessidades de saúde como conceito estruturante na luta pela integralidade e equidade na atenção à saúde. In: Pinheiro R, Mattos RA, organizadores. Os sentidos da integralidade na atenção e no cuidado à saúde. Rio de Janeiro: Abrasco; 2006. p. 115-128.

28. Silva JLL. O processo saúde-doença e importância para a promoção da saúde. Informe-se em promoção da saúde. 2006; 2(1):03-05.

29. Foucault M. O Nascimento da Clínica. Rio de Janeiro: Forense Universitária; 1998.

30. Minayo MCS. Saúde-doença: uma concepção popular da Etiologia. Cad. Saúde Pública. 1988; 4(4):363381.
31. Floriani CA, Schramm FR. Cuidados paliativos: interfaces, conflitos e necessidades. Ciênc. Saúde Colet. 2008; 13(supl2):2123-2132.

32. Viacava F, Travassos C, Oliveira EXG. Desigualdades geográficas e sociais no acesso aos serviços de saúde no Brasil: 1998 e 2003. Ciênc. Saúde Colet. 2006; 11(4):975-986.

33. Sontag S. Doença como metáfora: Aids e suas metáforas. São Paulo: Companhia das Letras; 2007.

34. Laplantine F. Antropologia da Doença. 4. ed. São Paulo: WMF Martins Fontes; 2010.

35. World Heath Association: definition of Palliative Care [internet]. [acesso em 2018 ago 5]. Disponível em: http://www.who.int/cancer/palliative/definition/en/.

36. Brasil. Ministério da Saúde, Comissão Intergestores Tripartite. Resolução MS/CIT n ${ }^{\circ} 41$ de 31 de outubro de 2018. Dispõe sobre as diretrizes para a organização dos cuidados paliativos, à luz dos cuidados continuados integrados, no âmbito Sistema Único de Saúde [internet]. Diário Oficial da União. 23 Nov 2018. [acesso em 2020 abr 6]. Disponível em: http:// www.in.gov.br/materia//asset_publisher/Kujrw0TZC2Mb/content/id/51520746/dol-2018-11-23-resolucao-n-41-de-31-de-outubro-de-2018-51520710.

37. Menezes, R. A. Em busca da boa morte: antropologia dos cuidados paliativos. Rio de Janeiro: Fiocruz; 2004.

38. Elias N. A solidão dos moribundos: seguido de envelhecer e morrer. Rio de Janeiro: Jorge Zahar; 2012.

39. Barbero J. El derecho del paciente a la información: el arte de comunicar. Anales Sis. San. Navarra. 2006; 29(supl3):19-27.

40. Chagas SM. Chamei a morte para a roda ela quis dançar ciranda, mudança: estudo descritivo do processo de cuidar diante da finitude [tese]. Rio de Janeiro: Faculdade de Medicina, Universidade Federal do Rio de Janeiro; 2016. 
41. Jardim DMB, Bernardes RM, Campos ACV, et al. Cuidar de pacientes terminais: experiência de acadêmicos de enfermagem durante estágio curricular. Rev. baiana saúde pública. 2011; 34(4):796-809.

42. Merleau-Ponty M. O visível e o invisível. 3. ed. São Paulo: Perspectiva; 1999.

43. Oliveira SG, Quintana AM, Budó MLD, et al. O enfrentamento da terminalidade pelos cuidadores fa- miliares durante a internação domiciliar. RENE.

2013;14(3):406-409.

44. Hesbeen W. Qualidade em enfermagem: pensamento e acção na perspectiva do cuidar. Lusociência: Lores; 2001.

Recebido em 27/05/2019

Aprovado em 13/01/2020

Conflito de interesses: inexistente

Suporte financeiro: não houve 